\title{
An Empirical Study on Critical Failure Factors and Business Intelligent System Failure at Pre-implementation Phase in Small and Medium Enterprises in Pakistan
}

\author{
Nimra Iffat ${ }^{1 *}$, Shahzad Chaudhry $\mathbf{M}^{\mathbf{2}}$, Bilal ${ }^{3}$, Wasif Ahmad ${ }^{4}$ and Anila Rabail ${ }^{\mathbf{1}}$ \\ ${ }^{1}$ University of the Punjab, Lahore, Pakistan \\ ${ }^{2}$ Government College University Lahore, Pakistan \\ ${ }^{3}$ University of Lahore, Pakistan \\ ${ }^{4}$ National College of Business and Economics, Lahore, Pakistan
}

\begin{abstract}
Business Intelligence is one of best way to analyze the critical capabilities of organization, but the implementation phases of these competences are frequently overwhelmed with tribulations. That's why many projects of such capabilities fail, while others succeed. The basic purpose of this research is to identify the critical failure factors (CFF) in the pre implementation phase of Business Intelligent $(\mathrm{BI})$ system and to test association between these critical factors. Small and Medium enterprises (SMEs) cannot be neglected in developing countries like Pakistan. They are chosen as target population because of its vital role in the development of economy such as creating employment opportunities, increasing GDP\%, increasing the volume of export etc. Based on four hundred and fifty respondents, the barriers of cost are valuing among top five with highest value of mean which are additional cost associated with the managing $\mathrm{BI}$, lack of financial resources, upfront cost, cost of obtaining $\mathrm{BI}$ software and setup cost respectively. This symbolizes the costing factor yet a foremost barrier in preponderance items in order to analyze $\mathrm{BI}$ in pre-implementation phase.
\end{abstract}

Keywords: Business Intelligence; Critical failure factor; Small and medium enterprises; Pre implementation phase

\section{Introduction}

The narration of successful business, in this industrialize uprising era is all about supervising, systemizing, measuring, monitoring and analyzing the transactional data with technology, proficiently and effectively. Undeniably, distinctiveness of contemporary organizations is the data revolution that has been steadily taking place over the last two decades. Many practitioners and scholars even see organizational and management decision making to be in the middle of a gradual transformation from an instinct- driven "art" to a progressively datadriven approach. Day to day massive amount of raw data is produced during every operational transaction in an organization [1]. BI converts information into knowledge with human judgment and intuitions. So we can say anecdotes of achievement now become yarn of managing intelligence [2].

According to "Howard Dresner" of Gartner research in 1989 BI is set of activities such as collecting, consolidating, organizing and presenting information in such approach which let the corporate world to craft the better business decisions toward their desired goals. $\mathrm{BI}$ is tool, technology or process within organizations ascertain thought provoking environment. BI makes the most of Business Processes and possessions in resourceful and proficient manner, improve the proactive decision making, curtail expenditure and capitalize the profit $[3,4]$ placed BI in the top ten strategic technologies for 2014. These results are consistent with those of the last five years, which show that organizations are still struggling to make progress with BI for profitability and productivity $[5,6]$.

The implementation of BI systems is colossal challenge. In business, it is allied not merely with advantages and benefits, but on the other hand, in some organization it also generates certain barricades, tribulations and risks. Not merely technology plays a vital part, but on top of all factors, such as community, processes, managing style and traditions of the organization, are also imperative. These factors frequently symbolize a huge predicament and can disrupt or avert attempts and efforts of deployment of an effectual BI solution for operating task of organizations. These factors are acknowledged as critical factors. The current purpose of study is to recognize CFF in pre implementation phase of BI system.

\section{Literature Review}

According to [7] CFF are basically set of tasks when arise as a hindrance before or after the implementation of BI. Its implementation is not a simple and easier chore; instead it entails the complex infrastructure, long term appropriate resources and development of decades [8]. According to [9-14] technological barriers to BI adoptions are; lack of skills to implement $\mathrm{BI} /$ data warehouse, lack of technology (pre-BI infrastructure), data security concerns (pervasive BI and outsourced version), frequent data latency issues, BI project complexity, BI tools highly specialized for wide spread use, complexities of data management, fragmented data sources in the enterprise. From organizational perspective barrier to $\mathrm{BI}$ adoption are running cost, lack of executive board interest, no real or tangible benefits, poor return of investment, lack of knowledge about BI product, implementation time lags. From environmental perspective are insufficient government supports for BI initiatives, lack of a complete BI Suite offering by any vendor, typical BI systems not optimized for OLTP. According to [15] critical factor for BI failures are management issues, changing

*Corresponding author: Nimra Iffat, University of the Punjab, Lahore 54890, Pakistan, Tel: +92 42 99231105; E-mail: nimm147@hotmail.com

Received September 02, 2015; Accepted October 17, 2015; Published October 26, 2015

Citation: Iffat N, Shahzad Chaudhry M, Bilal, Ahmad W, Rabail A (2015) An Empirical Study on Critical Failure Factors and Business Intelligent System Failure at Pre-implementation Phase in Small and Medium Enterprises in Pakistan. Bus Eco J 7: 193. doi:10.4172/2151-6219.1000193

Copyright: ( 2015 Iffat $\mathrm{N}$, et al. This is an open-access article distributed unde the terms of the Creative Commons Attribution License, which permits unrestricted use, distribution, and reproduction in any medium, provided the original author and source are credited. 
requirements and objectives, Justification and budget, organization and staffing, user issues, collaborative work problems, project planning and scheduling, data warehouse standards, tools and vendors, security, data quality, integration, data warehouse architecture, and performance.

According to [16] two manager aspect management and technology are found to be indispensable impediments in the BI system failure. They embrace top management support, change management, clear vision and mission, organizational culture, data information accuracy, sustainable data quality, suitability of hardware and system reliability.

Moreover, in literature reviews CFF are not only of technical or managerial nature but social factors also play vital part in this domain. Software and system of any organization comprises of three fundamentals elements which makes possible the successful running of project. These are people, technology and processes toward the implementation of different kind of strategies in organization: In corporate tactics management try to make alignment between BI system and organizational process to increase the effectiveness of business decision making, growth and development whereas in technology perspective strategies updation of technology, software's and advancement is integrated parallel.

Marie Barry [17] investigate the main areas of risk are scope creep, uncontrolled finances, Poor Communication, stake holder noninvolvement, skills shortage, unavailability of tools and technology, uncontrolled quality of deliverables, poor, wrong or no leader, technical difficulties, legal difficulties [18-26]. Identified common mistakes in implementing BI systems are; using ad hoc practices to select and fund BI project, providing inadequate governance to BI program management, establishing de facto program governance based on the initial BI projects, failing to strategically position $\mathrm{BI}$ in business organization, not providing adequate resources and funding needed for successful BI initiative.

\section{Research Problem}

Utters that organization do not demonstrate the failure of $\mathrm{BI}$ system execution. Nonetheless, BI failure rate is awfully high due to its complex structure [27]. This research paper is to find out the barriers of BI pre-implementation system in Pakistan. To make certain objectives of research being attained; the objectives were devised as follows:

1. Identify the BI adoption level in Pakistan.

2. To identify the significant BI CFF in SMEs Pakistan.

3. To analyze the association between failure of preimplementation phase of BI and its CFF in SMEs Pakistan.

\section{Research Questions}

The following research questions were devised for which research study has been conducted.

1. What is the BI adoption level in Pakistan?

2. What are significant BI CFF in pre implementation phase in SMEs Pakistan.

3. Is there is any association between failure of preimplementation phase of BI and its failure factor in SMEs Pakistan.

\section{Research Framework}

Figure 1 shows Framework of BI barriers in Pre-Implementation of BI system Failu Hypothesis Formulation.

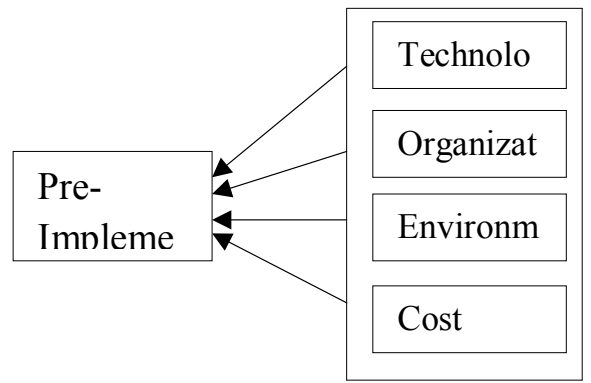

Figure 1: Framework of $\mathrm{BI}$ barriers in Pre-Implementation of BI system Failu.

\begin{tabular}{|l|c|}
\hline Category & \# Barriers \\
\hline Technological Barriers & 6 \\
\hline Organizational Barriers & 9 \\
\hline Environmental Barriers & 3 \\
\hline Financial Barriers & 6 \\
\hline Total & 24 \\
\hline
\end{tabular}

Table 1: Summary of BI Barriers based on Categories.

\begin{tabular}{|l|l|l|}
\hline Sr \# & Category & Factors \\
\hline 1 & Cost Factor & CF1:UpfrontCost \\
2 & & CF2: Setup Cost \\
3 & & CF3: Cost of Obtaining BI Software \\
4 & & CF4:AdditionalCostassociatedwithmanagingBI \\
5 & & CF5: Lack of Financial resource \\
6 & & CF6:Cost required to support management and training \\
\hline 7 & Organizational & OF1:Lack of executive board interest \\
8 & Factor & OF2: Lack of Knowledge about BI product \\
9 & & OF3:Lack of user oriented change management \\
10 & & OF4:Lack of Business centric championship \\
11 & & OF5:Lack of Business vision and Planning \\
12 & & OF6:Organizational resistance \\
13 & & OF7: Inadequate governance for BI program \\
14 & & OF8: Poor Business and BI alignment \\
15 & & OF9: Incomplete Business requirements \\
\hline 16 & Technological & TF1:Lack of Skill to handle BI program \\
17 & Factors & TF2:Lack of technology \\
18 & & TF3:Data Security Concerns \\
\hline 19 & & TF4:Poor Data Quality \\
20 & & TF5:BI Software complexity \\
21 & & TF6:Complexity of Data Management \\
\hline 22 & Environment & EF1:Insufficient Government support for BI initiatives \\
23 & Factor & EF2:Lack of user adoption \\
24 & & EF3:Lack of interest from user solution \\
\hline & &
\end{tabular}

Table 2: Detail of Factors for Research.

\section{Hypothesis Formulation}

H0: There is no significant relationship between failure of BI system in pre implementation phase and critical failure factors.

$\mathrm{H} 1$ : There is significant relationship between failure of BI system in pre implementation phase and critical failure factors.

\section{Research Methodology}

The research employs quantitative techniques to scrutinize the critical failure factors. SPSS is used for the empirical analysis through regression and Factor analysis [28-32]. Random sampling Techniques is used to collect the Data through questionnaire. Four hundred and fifty respondents participate in this research. The questionnaire is designed to collect information pertaining to demographic of respondents and company, BI adoption level, barriers to BI adoption [33-38] (Tables 1 and 2). 
Citation: Iffat N, Shahzad Chaudhry M, Bilal, Ahmad W, Rabail A (2015) An Empirical Study on Critical Failure Factors and Business Intelligent System Failure at Pre-implementation Phase in Small and Medium Enterprises in Pakistan. Bus Eco J 7: 193. doi:10.4172/2151-6219.1000193

Page 3 of 7

\section{Reliability test}

For consistency of BI barriers, a reliability test is demeanor to identify the Cronbach's alpha value. Value of Cronbach's alpha is 0.661 which is not acceptable [39-43]. A comprehensive analysis was conducted to perk up the Cronbach's alpha value. The decision to remove some factors is made from the table Cronbach's alpha value if the item has deleted [44-48].

\section{Cronbach's alpha value after extended research}

By removing 8 factors related to organizational and environment factor including OF1:Lack of executive board interest, OF2: Lack of Knowledge about BI product, OF3:Lack of user oriented change management, OF4:Lack of Business centric championship, OF5:Lack of Business vision and Planning, OF6:Organizational resistance, OF7: Inadequate governance for BI program, EF1:Insufficient Government support for BI initiatives, EF3: Lack of interest from user solution from reliability analysis, the value of Cronbach's alpha for barriers increased to 0.707 . Value is acceptable for further research and testing [49-53].

\section{Descriptive analysis}

A descriptive analysis was applied to portray the demographic of participants. The demonstration of the basic demographic characteristics includes gender, age, position and company industry [54-58].

\section{Demographic Profile}

Pie charts (Figures 2 and 3) demonstrate that collected sampling consists of $64.44 \%$ (288 participants) male and $35.56 \%$ (162 participants) female where mass participants were in the slot of 21-30 which consisted $42.67 \%$ (192 participants) [59-63]. There were $31.78 \%$

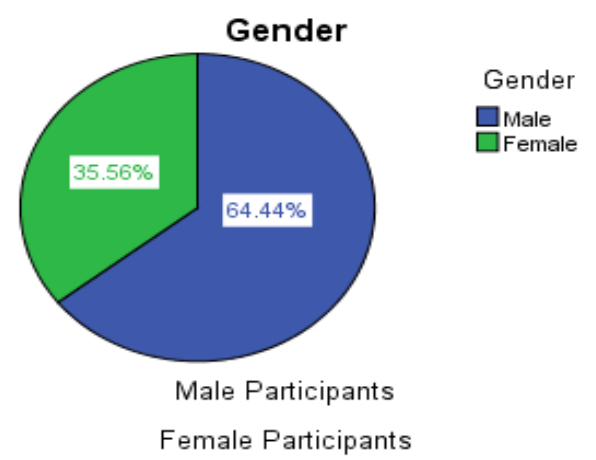

Figure 2: Pie chart demonstrate the collected.

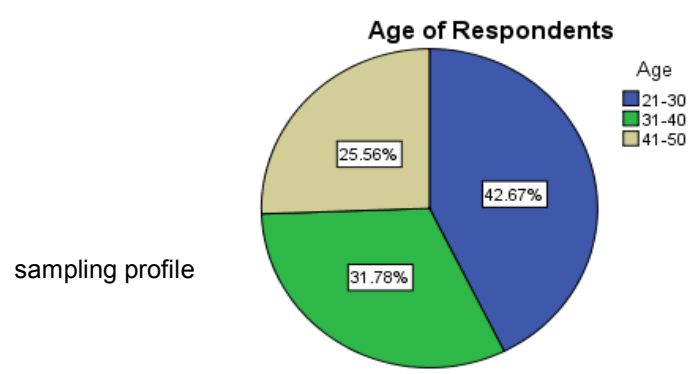

Figure 3: Pie chart demonstrate the collected.

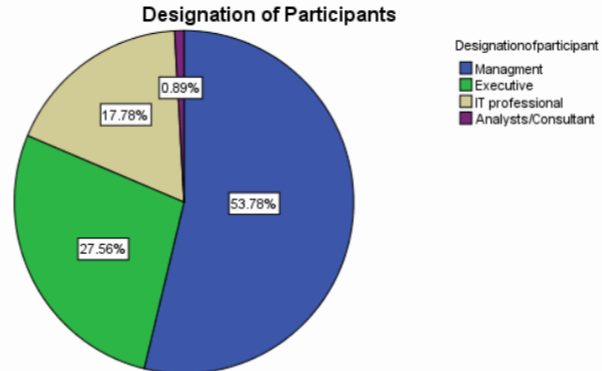

Figure 4: Pie chart presents categorization of employees.

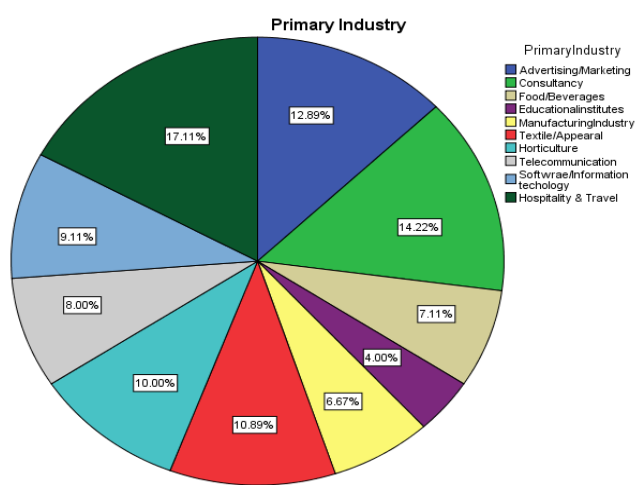

Figure 5: Different natures of organization's percentage are presented in pie chart.

(143 participants) resides into category of age from $31-40$ and $25.56 \%$ (115 participants) in age group of 41-50.

Pie chart (Figure 4) presents categorization of employees. Who works under the designation of business management or middle management in an organization consists of $53.87 \%$ (242 participants) and subsequently executive staff includes $22.1 \%$ (124 participants) [6470]. Afterward the position of IT Professionals were containing $17.78 \%$ (80 Participants), 0.89\% (40 participants) respectively.

Different natures of organization's percentage are presented in pie chart (Figure 5). Among all $12.89 \%$ data of respondents has been gathered from advertising/marketing industry, 4.225 from consultancy field, where as $7.11 \%$ data was assembled from food and beverages industry [71-75]. $4.00 \%$ of the respondents data was from Manufacturing industry, $6.67 \%$ from education and institutions, $10.89 \%$ from the Textile/Apparels, $10.00 \%$ from Horticulture, $8 \%$ from the telecommunication franchises sector, $9.11 \%$ from were serviced in information technology and $17.11 \%$ are listed in hospitality and travel sector [75-80].

\section{Means and standard deviation}

The mean and standard deviation for twenty four BI barriers describe in Table 3 were chosen to categorize the important barriers by measure up to the mean value. The highest value of mean demonstrate the vital barrier where the lowest value of mean shows the nonimportant barriers of BI during pre-implementation phase of BI system $[81,82]$.

Based on four hundred and fifty respondents, the barriers of cost are valuing among top five with highest value of mean which 


\begin{tabular}{|l|c|c|c|}
\hline BI Barriers & N & Mean & Std. Deviation \\
\hline $\begin{array}{l}\text { CF4:AdditionalCostassociatedwithmanagin } \\
\text { gBI }\end{array}$ & 450 & 3.7756 & 1.01034 \\
\hline CF5:LackofFinancialresource & 450 & 3.7533 & 2.62489 \\
\hline CF1:UpfrontCost & 450 & 3.7200 & 1.47490 \\
\hline CF3:CostofObtaningBISoftware & 450 & 3.6889 & .99715 \\
\hline CF2:SetupCost & 450 & 3.3533 & 1.23319 \\
\hline TF1:LackofSkilltohandleBlprogram & 450 & 3.3089 & 1.46683 \\
\hline $\begin{array}{l}\text { CF6:Costrquiredtosupportmanagmentandtra } \\
\text { ining }\end{array}$ & 450 & 3.2333 & 1.30145 \\
\hline TF5:BISoftwarecomplexity & 450 & 3.1733 & 1.33355 \\
\hline OF9:IncompleteBusinessrequirements & 450 & 2.9400 & 1.41373 \\
\hline OF8:PoorBusinessandBlalignment & 450 & 2.9200 & 1.37032 \\
\hline TF3:DataSecurityConcerns & 450 & 2.8911 & 1.36751 \\
\hline TF2:Lackoftechnology & 450 & 2.8556 & 1.44968 \\
\hline TF4:PoorDataQuality & 450 & 2.8000 & 1.45305 \\
\hline TF6:ComplexityofDataManagment & 450 & 2.7867 & 1.58608 \\
\hline OF3:Lackofuserorientedchangemanagment & 450 & 2.2378 & 1.60980 \\
\hline EF2:Lackofuseradoption & 450 & 1.4600 & 1.07800 \\
\hline Valid N (listwise) & 450 & & \\
\hline
\end{tabular}

Table 3: Describe the mean and standard deviation for twenty four BI barriers.

\begin{tabular}{|c|c|c|}
\hline & Category & BI Barriers \\
\hline \multirow{6}{*}{1} & \multirow{6}{*}{$\begin{array}{l}\text { Technological } \\
\text { Factor }\end{array}$} & TF1:Lack of Skill to handle BI program \\
\hline & & TF2:Lack of technology \\
\hline & & TF3:Data Security Concerns \\
\hline & & TF4:Complexity of Data Management \\
\hline & & TF5:BI Software complexity \\
\hline & & TF6:Poor Data Quality \\
\hline \multirow{6}{*}{2} & \multirow{6}{*}{ Cost Factor } & CF1:Upfront Cost \\
\hline & & CF2:Setup Cost, \\
\hline & & CF3:Cost of Obtaining BI Software Additional \\
\hline & & CF4:Cost associated with managing $\mathrm{BI}$ \\
\hline & & CF5:Lack of Financial resource \\
\hline & & CF6:Cost required to support management and training \\
\hline \multirow{3}{*}{3} & \multirow{3}{*}{$\begin{array}{l}\text { Organizational } \\
\text { Factor }\end{array}$} & OF9:Poor Business and $\mathrm{BI}$ alignment \\
\hline & & OF10:Lack of user oriented change management \\
\hline & & OF3:Incomplete Business requirements \\
\hline 4 & $\begin{array}{l}\text { Environmental } \\
\text { Factor }\end{array}$ & EF2:Lack of User adoption \\
\hline
\end{tabular}

Table 4: Represents various Categories of BI Barriers.

are Additional cost associated with the managing BI, Lack of financial resources, Upfront cost, Cost of obtaining BI software and Setup cost respectively [83]. This symbolizes the costing factor yet a foremost barrier in preponderance items in order to analyze BI in pre implementation phase.

\section{Factor component analysis}

KMO and bartlett's test: Value of KMO is 0.754 it represent the sampling adequacy is at satisfactory level. Bartlett's test of sphericity is significant with the value of 0.000 . It is small enough to reject the null hypothesis. This means that correspondence matrix is not an identity matrix [84].

\section{Principle component analysis:}

Total variance explained: The Table 1 , Appendix shows all the factors involved in research study extractable from the scrutiny along with their eigenvalues, In this analysis, there are four factors with eigenvalues higher than 1 . The "percentage of variance" values enlighten that how much of the total variability can be calculated by each of these abstract factors. Factor 1 report for $21.275 \%$ of the variability in all 16 variables, factor 2 accounts for $10.467 \%$ of the variability in all and so on. All the remaining factors are not significant. Cumulative percent column accounts for $47.117 \%$ variability among all 16 variables.

Component matrix: The Table 2, Appendix demonstrates the loadings of the sixteen factors into four factors. The slit on the table symbolize loadings that have value less than 0.5 . We covered up all loadings less than value of 0.5 .

\section{Regression analysis}

Regression analysis conducted to identify the association/ relationship between sixteen barriers extracted through factor analysis. Sixteen barriers are categorized into four major factors which are further used as independent variables to predict failure of BI system as the solely dependent variable [71] (Table 4).

Regression analysis on critical technological barriers against failure of BI system: Based on regression result in (Table 3, Appendix), the P-value in ANOVA is 0.001 which is less than 0.05. Therefore, there is significant relationship between critical technological barriers and BI System failure.

$\mathrm{R}$ square $\left(\mathrm{R}^{2}\right)$ is interpreted as the correlation coefficient squared and also said to be coefficient of determination. There is $2 \%$ of total of $\mathrm{Y}$ (failure of BI pre implementation phase) explained by the regression model consisting six technological barrier mentioned in Table 4 .

Regression analysis on critical costing barriers against failure of BI system: Based on regression result represented in Table 4, Appendix, the $\mathrm{P}$-value in ANOVA is 0.000 which is less than 0.05. Therefore, there is significant relationship between critical cost barriers and BI System failure.

R square $\left(R^{2}\right)$ value represents there is $4 \%$ of total of $Y$ (failure of BI pre implementation phase) explained by the regression model consisting six costing barriers mentioned in Table 4.

Regression analysis on critical environmental barriers against failure of BI system: Based on regression result represented in Table 5, Appendix, the P-value in ANOVA is 0.266 which is greater than 0.05 . Therefore, there is no significant relationship between critical environmental barriers and BI System failure. $\mathrm{R}$ square (R2) is interpreted as there is $0.3 \%$ of total of $\mathrm{Y}$ (failure of BI pre implementation phase) explained by the regression model consisting one environmental barrier mentioned in Table 4.

Regression analysis on critical organizational barriers against failure of BI system: Based on regression result represented in Table 6, Appendix the P-value in ANOVA is 0.000 which is less than 0.05 . Therefore, there is significant relationship between critical environmental barriers and BI System failure.

$\mathrm{R}$ square $\left(\mathrm{R}^{2}\right)$ is interpreted as there is $3 \%$ of total of $\mathrm{Y}$ (failure of $\mathrm{BI}$ pre implementation phase) explained by the regression model consisting three organizational barriers mentioned in Table 4.

Overall significance of the model: In the model summary Table 7, Appendix, facilitates to measure about the fitness of the model. Value of R-squared varies between 0 and 1 . In this case it is 0.136 , so $13 \%$ of the variance in failure of BI system at pre-implementation phase can be explained by organizational factors, environmental factors, costing factors and technological Factors. The column standard error of the estimate helps to measure of how much $\mathrm{R}$ is predicted to vary from 
Citation: Iffat N, Shahzad Chaudhry M, Bilal, Ahmad W, Rabail A (2015) An Empirical Study on Critical Failure Factors and Business Intelligent System Failure at Pre-implementation Phase in Small and Medium Enterprises in Pakistan. Bus Eco J 7: 193. doi:10.4172/2151-6219.1000193

Page 5 of 7

one sample to the next. Here the value of standard error of estimate is 1.19557.

Based on regression result represents the P-value in ANOVA is $0.000,0.000$ and 0.001 for technological, cost and organizational barriers which is less than 0.05 . Therefore, there is significant relationship between critical barriers and BI System failure.

Whereas $\mathrm{P}$ value of environmental barriers is 0.328 which is higher than 0.05. It represents that there is no significance relationship between the environmental barriers and failure of BI system.

In coefficient table summary size of the coefficient for each independent variable measure the intensity of the outcome that variable is having on the dependent variable along with the directions. First coefficient of cost factor demonstrating that [80]. 552 of the failure of BI system variable is expected to increase when that cost barriers variable increases by one, holding all other variables(environmental, technological and organizational) constant. Second coefficient of technological factor demonstrating that -.319 of the Failure of BI system variable is expected to decrease when that technological barriers variable increases by one, holding all other variables(environmental, cost and organizational) constant. Third coefficient of environmental factor demonstrating that 0.051 of the failure of BI system variable is expected to increase when that environmental barriers variable increases by one, holding all other variables (cost, technological and organizational) constant. Fourth coefficient of cost factor demonstrating that -.210 of the failure of BI system variable is expected to decrease when that organizational barriers variable increases by one, holding all other variables (environmental, technological and cost) constant.

\section{Tools and software other than BI}

Pie charts in Figure 6 characterize what kind of technology organization adopted other than BI. The collected sampling consists of 40.67\% who adopted Microsoft Access for data base management and business operations [75]. 17.33\% using Microsoft excel, 16.22\% using database management system, $15.11 \%$ using homegrown systems and software according to their feasibility.

\section{Findings and Conclusion}

Research study prevail the BI adoption level in Pakistan. Only 2 percent organizations of SMEs using BI system for their decision making others are using different kind of tools for the effective management. So it clearly identifies the usage of BI system. This has

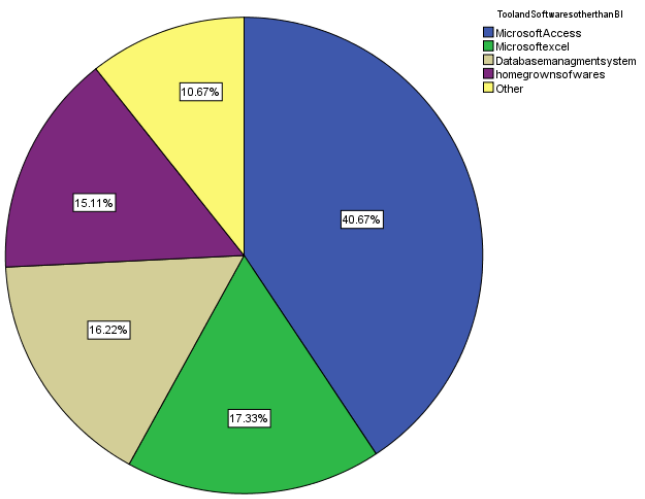

Figure 6: Pie charts characterize what kind of technology organization adopted other than $\mathrm{BI}$ answered the research question one 'What are the adoption levels in SMEs of Pakistan? In further study some significance barriers identify essentially impacting the corporate decision to adopt BI modules. Through reliability analysis some factors were removed and to check the significance of remaining factors, Factor component analysis testing were performed.

By evaluating the result between descriptive and regression, four hundred and fifty respondents, the barriers of cost are valuing among top five with highest value of mean which are Additional cost associated with the managing BI, Lack of financial resources, Upfront cost, Cost of obtaining BI software and Setup cost respectively. This symbolizes the costing factor yet a foremost barrier in preponderance items in order to analyze BI in pre implementation phase.

The three top lowest mean scores which less agreed by respondents are Poor Data Quality, Complexity of Data management, Lack of Business Vision and Planning. Their mean scoring are from range 2.76 to 1.46 which is close to neutral score. This helps to explain the most significance factors as a critical barrier toward the implementation of $\mathrm{BI}$ in the pre-implementation Phase.

Through regression analysis among the four critical barriers categorized as Organizational Barriers, Technological barriers, Cost barriers and environmental barriers three barriers are associated with Failure of BI system. On the other hand environmental barriers are insignificant with the failure of BI system.

\section{References}

1. Al-maaitah MA (2013) The Role of Business Intelligence Tools in Decision Making Process. International Journal of Computer Applications 73: 88-97.

2. Wieder B, Ossimitz ML, Chamoni $P$ (2012) The Impact of Business Intelligence Tools on Performance: A User Satisfaction Paradox? International Journal of Economic Sciences and Alied Research 5: 7-32.

3. Ranjan J (2009) Business Intelligence: Concepts, Components, Techniques and Benefits. Journal of Theoretical and Applied Information technology 61-70.

4. Adelman S, Bischoff J (2002) Impossible Datawarehouse Situations. Solutions from the Expert. Pearson Education.

5. Ana-Maria MC (2010) Evolution of Decision Suort Systems Research Field in Numbers. Informatica Economic 14: 70-78.

6. Arendt $L$ (2008) Barriers to ICT adoption in SMEs. Journal of Systems and Information Technology 10: 93-108.

7. Atre LT (2003) Business Intelligence Roadmap. Decision-Suort Applications $16-25$

8. Moss L, Atre S (2003) Business intelligence roadmap. The complete lifecycle for decision-suort alications. Boston: Addison-Wesley.

9. Ariss SS, Raghunathan TS, Kunnathar A (2000) Factors affecting the adoption of advanced manufacturing technology in small firms. SAM Advanced Management Journal 65: 14-29.

10. Sangar AB, lahad NBA (2013) Critical Factors That Affect The Success Of BIS international journal of scientific \& technology research 2: 176-180.

11. Moss TL, Atre S (2003) Business Intelligence Roadmap: The Complete Project Lifecycle for Decision-suort Alications, Addison-Wesley, Boston.

12. Weber M (2013) Keys to sustainable self-service Business Intelligence. Business Intelligence Journal 18: 18-24

13. Armstrong R, Gallo J, Williams S (2013) BI experts' perspective. Business Intelligence. Business Intelligence Journal 18: 40-45.

14. Azvine B, Cui Z, Nauck DD (2005) Towards real-time business intelligence. BT Technology Journal 23: 214- 225

15. Arnott D, Pervan G (2005) A critical analysis of decision suort systems research Journal of Information Technology 20: 67-87.

16. Srichai NT (2011) Dimensions influencing Business Intelligence usage in 
Citation: Iffat N, Shahzad Chaudhry M, Bilal, Ahmad W, Rabail A (2015) An Empirical Study on Critical Failure Factors and Business Intelligent System Failure at Pre-implementation Phase in Small and Medium Enterprises in Pakistan. Bus Eco J 7: 193. doi:10.4172/2151-6219.1000193

Page 6 of 7

Thailand SMEs. International Conference on Management and Artificial Intelligence 6: 32-36

17. Atre S (2008) The Top 10 critical challenges for business intelligence success Computerworld Custom Publishing.

18. Eckerson W, White C (2003) Evaluating ETL and data integration platforms. The Data Warehouse Institute Report Series 1-40.

19. Bacon CJ (1992) The Use of Decision Criteria in Selecting Information Systems/ Technology Investments. MIS Quarterly 16: 335-353.

20. Olszak CM, Ziemba E (2006) Business intelligence systems in the holistic infrastructure development suorting decision-making in organizations. Interdisciplinary Journal of Information, Knowledge and Management 1: 47-58.

21. Buckhout S, Frey E, Nemec J (1999) Making ERP succeed: Turning fear into promise. Journal of Strategy \& Business 15: 60-72.

22. Blumberg RA (2003) More than Search. DM Review 42-47.

23. Burton B, Geishecker L, Hostmann B (2006) Organizational Structure: business intelligence and Information Management. Gartner Research.

24. Bucher T, Gericke A, Sigg S (2009) Process-centric business intelligence Business Process Management Journal 15: 408-429.

25. Bussen W, Myer D (1997) Executive information system failure: A New Zealand case study. Journal of Information Technology 12: 145-153.

26. Buchda S (2007) Rulers for Business Intelligence and Competitive Intelligence: An Overview and Evaluation of Measurement Aroaches. Journal of Competitive Intelligence and Management 4.

27. Chau PYK, Tam KY (1997) Factors Affecting the Adoption of Open Systems: An Exploratory Study. MIS Quarterly 21: 1-24.

28. Chang HH (2006) Technical and management perceptions of enterprise information systems importance, implementation, and benefits. Information Systems Journal 16: 263-292.

29. Chen H, Chiang RHL, Storey VC (2012). Business intelligence and analytics: From big data to big impact. MIS Quarterly 36: 1165-1188.

30. Chervinsky H, Henderson D (1997) Building a cost effective data warehouse. Cost and Management 71: 19-22.

31. Dennis AR, George JF, Jessup LM, Nunamaker JF, Vogel VR (1988) Information technology to suort electronic meetings. MIS Quarterly 12: 591-624.

32. Eom SB (2008) Decision Support Systems. International Encyclopedia of Business and Managment 15.

33. Fuchs $\mathrm{G}$ (2006) The vital $\mathrm{BI}$ maintenance process in business intelligence implementation: Issues and perspectives. ICFAI University Press 116-123.

34. Howson C (2006) Seven pillars of BI success - BI tools are getting better, but technology is only part of the story. Intelligent Enterprise 1: 33-37.

35. Hannula M, Pirttimäki V (2003) Business Intelligence - Empirical Study on the Top 50 Finnish Companies. Journal of American Academy of Business 2: 593-600.

36. Leidecker J, Bruno A (1987) CSF analysis and the strategy development process. In B. Taylor (Ed.), Strategic planning and management handbook 333-351.

37. Luhn HP (1958) A business intelligence system. IBM Journal of Research and Development 2: 314-319.

38. Lonnqvist A, Pirttimaki V (2006) The measurement of business intelligence Information Systems Management 23: 32-40.

39. McLean WH (1992) Information systems success: The quest for the dependent variable. Information Systems Research 7: 60-95.

40. McDowell D (1997) Strategic intelligence and analysis. The Criminal Environment, Intelligence and Strategic Analysis 6-10.

41. Miller S (2007) Open Source BI as Disruptive Technology. DM Review 17: 14-36.

42. Mohammad HA (2012) The Impact of Business Intelligence and Decision suor on the Quality of Decision Making. Middle East University 74-90.

43. Mukherjee D, D'Souza D (2003) Think phased implementation for successful data warehousing. Information Systems Management 20: 82-90.

44. Ramanigopal GP (2012) Business intelligence for competence in consumer packaged good industry. International journal of marketing and technology 15-22.

45. NAV MD (2007) Business Intelligence: Driving better business performance for companies with changing needs.

46. Mc Murchy N (2008) Toolkit Tactical Guideline: Five Success Factors for Effective BI Initiatives.

47. Ngai EWT, Cheng TCE, Ho SSM (2004) Critical success factors of web-based suly-chain management systems: an exploratory study. Production Planning \& Control 15: 622-630.

48. Negash S (2004). Business intelligence. Communications of Association for Information Systems 13: 177-195.

49. Negash S, Gray P (2008) Business intelligence. In F. Burstein, CW Holsale (Eds.), Decision suopprt systems, Berlin: Springer 175-193.

50. Shimaa O, Nasr M (2011) The Cloud Computing: The Future of BI in the Cloud International Journal of Computer Theory and Engineering 3: 750-754.

51. Olszak CM, Ziemba E (2007) Approach to Building and Implementing Business Intelligence Systems. Interdisciplinary Journal of Information, Knowledge, and Management 2: 135-148.

52. Oksana JH (2010) Business Intelligence for Small and Medium Enterprise. Sigmod Record 50: 2-5.

53. O'Brien JA, Marakas GM (2007) Introduction to information systems. New York: McGrawHill.

54. Olszak CM, Ziemba E (2003) Business intelligence as a key to management of an enterprise. In E.Cohen, and E. Boyd (Eds.), Proceedings of Informing Science and IT Education InSITE'2003. Santa Rosa: The Informing Science Institute.

55. Olszak CM, Ziemba E (2008) The conceptual model of a web learning porta for small and medium sized enterprises. The Journal of Issues in Informing Science and Information Technology 5: 335-351.

56. Olszak CM, Ziemba E (2010a) Business performance management for competitive advantage in the information economy. Journal of Internet Banking and Commerce 15: 93-104.

57. Olszak CM, Ziemba E (2010b) Knowledge management curriculum development: Linking with real business needs. Issues in Informing Science and Information Technology 7: 235-248.

58. Olszak CM, Ziemba E (2011a) Communities of practice in knowledge management and organizational learning. Technologies for supporting reasoning communities and collaborative decision making: Cooperative approaches 76-93.

59. Olszak C, Ziemba E (2007) Approach to building and implementing business intelligence systems. Interdisciplinary Journal of Information Knowledge and Management 2: 135-138.

60. Parr A, Shanks G (2000) A model of ERP project implementation. Journal of Information Technology 15: 289-303.

61. Poon PP, Wagner C (2001) Critical success factors revisited: success and failure cases of information systems for senior executives, Decision Support Systems 30: 393-418.

62. Rockhart JF (1979) Critical Success Factors. Harvard Business Review 32 81-91

63. Rajteric IH (2010) Overview of Business Intelligence maturity models Management 15: 47-67.

64. Rainer RK, Watson H (1995) What Does it Take for Successful Executive Information Systems. Decision Support Systems 14: 147-156.

65. Rieger B (2005) Knowledge Management and Business Intelligence.

66. Ramamurthy KR, Sen A, Sinha AP (2008) An empirical investigation of the key determinants of data warehouse adoption. Decision Support Systems 44 817-841.

67. Remus U (2006) Critical success factors of implementing enterprise portals 39th Hawaii International Conference on System Sciences, Hawaii: 538-552.

68. Rockart J (1979) Chief executives define their own data needs. Harvard Business Review 81-93.

69. Rowan J (2003) Design techniques for a business intelligence solution. Data Base Management 28: 1-8. 
Citation: Iffat N, Shahzad Chaudhry M, Bilal, Ahmad W, Rabail A (2015) An Empirical Study on Critical Failure Factors and Business Intelligent System Failure at Pre-implementation Phase in Small and Medium Enterprises in Pakistan. Bus Eco J 7: 193. doi:10.4172/2151-6219.1000193

70. Saunders M, Lewis P, Thornhill A (2007) Research methods for business students. ( $5^{\text {th }}$ edn), London: Prentice Hall.

71. Sammon D, Finnegan $P(2000)$ The Ten Commandments of Data Warehousing Database for Advances in Information Systems 31: 82-91

72. Sharp S (2004) Build better decisions: strategies for reducing risk and avoiding surprises. Handbook of business strategy 5: 125-131.

73. Shin B (2003) An Exploratory Investigation of System Success Factors in Data Warehousing. Journal of the Association for Information Systems 4: 141-170.

74. Solomon MD (2005) Ensuring A Successful Data Warehouse Initiative. Information Systems Management 22: 26-36.

75. Srikant S, (2006) Logical Data Modeling: A Key to Successful Enterprise Data Warehouse implementations. DM Review 16: 13-16.

76. Srivastava J, Chen PY (1999) Warehouse Creation - A Potential Roadblock to Data Warehousing. Knowledge And Data Engineering, IEEE Transactions 11: 188-127.

77. Strong DM, Lee YW, Wang RY (1997) Data quality in context, Communications of the ACM 40: 103-110.
78. Sumner M (2000) Risk factors in enterprise-wide/ERP projects, Journal of Information Technology 15: 317 - 327

79. Vosburg J, Kumar A (2001) Managing dirty data in organizations using ERP Lessons from a case study. Industrial Management and Data Systems 101: 21-31.

80. Walsham G (1993) Interpreting Information Systems in Organizations, John Wiley and Sons, New York, USA.

81. Watson HJ, Haley JB (1998) Managerial Considerations, Communications of the ACM 41: 32-37.

82. White MD, Marsh EE (2006) Content analysis: A flexible methodology. Library Trends 55: 22-45.

83. Wang $\mathrm{H}$, Wang $\mathrm{S}$ (2008) A knowledge management approach to data mining process for business intelligence. Industrial Management \& Data Systems 108: $622-634$.

84. Yeoh W, Koronios A (2010) Critical success factors for Business Intelligence systems. Journal of Computer Information Systems 50: 23-32. 